\title{
Impact of physical activity levels on \\ cardiometabolic parameters and autonomic modulation in elderly: a cross-sectional study
}

\section{Ariane Viana}

Universidade Nove de Julho - Campus Vergueiro

\section{Neide Bugliani}

Universidade Sao Judas Tadeu

\section{Michelle Sartori}

Universidade Sao Judas Tadeu

Camila Martins da Silva

Universidade Sao Judas Tadeu

Iris Callado Sanches

Universidade Sao Judas Tadeu

Marília Velardi

Universidade Sao Judas Tadeu

Maria Luiza de Jesus Miranda

Universidade Sao Judas Tadeu

Katia De Angelis ( $\sim$ prof.kangelis@yahoo.com.br)

Universidade Federal de São Paulo, UNIFESP https://orcid.org/0000-0002-3640-9049

\section{Research article}

Keywords: heart rate variability, erdely, physical activity

Posted Date: February 4th, 2020

DOI: https://doi.org/10.21203/rs.2.22584/v1

License: (c) (1) This work is licensed under a Creative Commons Attribution 4.0 International License. Read Full License 


\section{Abstract}

Background: By 2030, approximately $20 \%$ of the population worldwide will be 65 years of age or older. In this age group, cardiovascular diseases (CVD) will result in $40 \%$ of all deaths. Heart rate variability (HRV) appears to be reduced under stress conditions and in many chronic diseases as cardiovascular diseases that appear to be associated with autonomic changes that usually include decreased parasympathetic activation and/or increased sympathetic modulation. Thus, aging is very important for altering neurohumoral mechanisms that control the cardiovascular system.

Objective: To analyze the influence of level of physical activity in the HRV in elderly people.

Methods: Cross-sectional analytical study which included 49 subjects (60 - 86 years), which answered the Baecke questionnaire.

Results: The less physically active group had lower levels of plasma HDL $(42 \pm 2.43 \mathrm{mg} / \mathrm{dL}$ vs $52 \pm 3.8 \mathrm{mg} / \mathrm{dL})$ and higher systolic BP $(131 \pm 117 \mathrm{mmHg}$ vs $117 \pm 4.07 \mathrm{mmHg})$ when compared to the most active group. The more physically active group showed higher $\mathrm{PI}$ of variance $\left(1849.6 \pm 387.7 \mathrm{~ms}^{2}\right)$ when compared to the moderate $\left(892.1 \pm 141.9 \mathrm{~ms}^{2}\right)$ and the less physically active groups $\left(972.3 \pm 285.2 \mathrm{~ms}^{2}\right)$. Moreover, the most physically active group presented lower LF/HF balance $(1.6 \pm 0.2)$ when compared to the moderate $(2.6 \pm 0.3)$ and the less active groups $(2.5 \pm 0.2)$.

Discussion: The results demonstrated the importance of physical activity to promote hemodynamic, autonomic and lipid profile improvement, suggesting a lower risk of developing or progressing the disease in the elderly.

\section{Introduction}

Aging can lead to a gradual loss of physiological reserves, increasing the risk of contracting various diseases and a general decline in the individual's intrinsic capacity (1).

By 2030, approximately $20 \%$ of the population worldwide will be 65 years of age or older. In this age group, cardiovascular diseases (CVD) will result in $40 \%$ of all deaths (2). CVD accounts for $29.6 \%$ of deaths worldwide (3), and for $30 \%$ of deaths in Brazil (4). Data show that $40.6 \%$ of the deaths were caused by high blood pressure, $13.7 \%$ because of smoking, $13.2 \%$ related to poor diet, $11.9 \%$ as a consequence of sedentary lifestyle and $8.8 \%$ due to changes in the blood glucose level (5).

Heart rate variability (HRV) appears to be reduced under stress conditions and in many chronic diseases (6) as cardiovascular diseases that appear to be associated with autonomic changes that usually include decreased parasympathetic activation and/or increased sympathetic modulation. Thus, aging is very important for altering neurohumoral mechanisms that control the cardiovascular system (7). Although studies on the effects of exercise are still conflicting, there is evidence that aerobic training may increase HRV and cardiac vagal tone both in healthy individuals and in patients with chronic diseases $(6,7,8)$. 
Considering the population's aging increase and the consequent increase in cardiovascular risk, in addition to the increasingly sedentary changes in the lifestyle of the population, it is necessary to study the influence of the level of physical activity on the aging process and factors that influence the development of cardiovascular diseases. Thus, in this study, we tested the hypothesis that the level of physical activity in the elderly is associated with different values of HRV. In this sense, our objective was to analyze the influence of the level of physical activity on the modulation of the autonomic nervous system and on cardiometabolic variables in the elderly.

\section{Materials And Methods}

This is a cross-sectional analytical study. The subjects of this study were individuals participating in a program called "Project Senior with Active Life of São Judas Tadeu University". The Project was submitted to the Research Ethics Committee (COEP/USJT) under number 0067.0.219.000-09. All the participants signed Informed Consent Form.

The sample was composed by 49 individuals, 9 men and 40 women that attended the inclusion criteria: to pertain to the lower socio-economic status (earning till 5 minimum wages per month); to belong to levels 3 and 4 of functional status: independent and inactive (level 3 ) and active (level 4); being between 60 and 86 years old and with read and write skills.

\subsection{Habitual Physical Activity Questionnaire (Baecke Questionnaire) and Anamnese}

To measure the level of physical activity, the individuals answered the Baecke questionnaire. This questionnaire is composed by 16 questions and measures the habitual physical activity in the last 12 months (Alex Antonio Florindo \& Latorre, 2003; (10). The anamnese questionnaire, composed by 12 questions, measured the lifestyle, medical history and physical activity throughout life.

\subsection{Anthropometric data}

The body mass index (BMI= the weight divided by height squared) was calculated to verify if the individuals were overweight or obese.

\subsection{Blood arterial pressure}

The individual remained at rest for 15 minutes in a closed room, sitting in a comfortable position, with the legs uncrossed and feet flat. After this period, the blood pressure was measured 3 times at intervals of 02 minutes. The method used was the auscultation following the recommendations of the Brazilian Society of Hypertension and Guideline to American College of Cardiology (2017), using stethoscope and sphygmomanometer of Litman® $(4,11)$.

\subsection{Biochemical Analysis}


The participants attended other day in the laboratory of chemical analyzes at University São Judas Tadeu to collect blood samples, state fasting 12 hours. Tubes were collected for biochemical analyzes (blood without anticoagulant) and determination of blood glucose level (fluoride anticoagulant). The blood without anticoagulant was centrifuged and from the serum were analyzed: LDL, HDL, VLDL and triglycerides.

\subsection{Heart Rate Variability}

The HRV was measured by the record of the R-R interval (ms), through the Polar frequency meter, model RS800®. In that HR monitor, the transmitter belt detects the electrocardiographic signal beat-by-beat and transmits it through an electromagnetic wave to the Polar wrist receptor, where this information is digitalized, displayed and stored. This system detects the ventricular depolarization corresponding to the $\mathrm{R}$ wave of the electrocardiogram, with sampling frequency of $500 \mathrm{~Hz}$ and time resolution of $1 \mathrm{~ms}$ which was previously validated against standard electrocardiograph by Holter (12). The recording files were transferred to the Polar Precision Performance Software through the Interface Infrared, or IrDA, which allows the exercise data bidirectional exchange with a microcomputer for subsequent analysis of the interval variability of cardiac pulse in the different recorded situations. The R-R intervals (PI) originated from the frequency meter were converted and stored in an Excel file and it was visually verified to identify and/or correct some incorrect marking. The data were analyzed and charted through the MATLAB program in the format of the Fast Fourier Transform (FFT). After this mathematical remodeling, the absolute potencies were obtained in the respective pre-set frequency bands: low frequency (LF, 0.04-0.15 $\mathrm{Hz})$ and high frequency $(\mathrm{HF}, 0.15-0.4 \mathrm{~Hz})$. The data are expressed in normalized units. The LF component is used as an index of sympathetic modulation. The HF component is used as an index of the parasympathetic modulation. The LF/HF ratio indicates the sympathovagal balance. The detection of the R-R intervals obtained in the frequency meter will follow the same criteria previously described for the design of the time sets of the variability in the frequency domain (13). For this study the total variance was used as an index in the time domain.

\subsection{Statistical analysis}

The InStat ${ }^{\circledR}$ software (Version 3.0) was used to analyze parametric data. The results are presented in mean \pm standard error of the mean. ANOVA followed by Newman Keuls Student's post hoc was used for statistical analysis. The significance level adopted was $5 \%$. The power of the sample was calculated $a$ posteriori considering the variances of the groups for the Variance of IP obtaining a $\beta$ of 1.0.

\section{Results}

The sample consisted for 49 individuals, with 9 men and 40 women, aging $70 \pm 9.97$ years. The BMI was $27.6 \pm 3.95 \mathrm{Kg} / \mathrm{m}^{2}$ (Table 1). There was no difference in BMI considering the different levels of physical activity (Table 1). Between the individuals analyzed, we noted that $3.43 \%(7)$ were taking medication for dyslipidemia, $1.96 \%$ (4) for diabetes and $9.31 \%$ (19) for hypertension. 
Table 1. Demographics and clinical characteristics.

\begin{tabular}{lccc}
\hline & $\begin{array}{c}\text { Active } \\
(\mathrm{n}=13)\end{array}$ & $\begin{array}{c}\text { Moderate Active } \\
(\mathrm{n}=19)\end{array}$ & $\begin{array}{c}\text { Less Active } \\
(\mathrm{n}=17)\end{array}$ \\
\hline Age (years) & $70.83 \pm 2.28$ & $69.68 \pm 1.67$ & $69.18 \pm 1.60$ \\
BMI (Kg/m $\left.{ }^{2}\right)$ & $27.11 \pm 1.26$ & $28.13 \pm 1.21$ & $28.40 \pm 1.13$ \\
\hline Fasting blood glucose & $100 \pm 4.33$ & $104 \pm 4.76$ & $101 \pm 5.55$ \\
(mg/dL) & & & \\
\hline Total cholesterol (mg/dL) & $179 \pm 1.75$ & $190 \pm 12.12$ & $186 \pm 9.80$ \\
\hline HDL (mg/dL) & $52 \pm 3.08$ & $45 \pm 2.40$ & $42 \pm 2.43^{*}$ \\
\hline LDL (mg/dL) & $105 \pm 3.91$ & $118 \pm 10.87$ & $118 \pm 9.11$ \\
\hline VLDL (mg/dL) & $24 \pm 2.91$ & $26 \pm 2.55$ & $25 \pm 3.18$ \\
\hline Triglycerides (mg/dL) & $105 \pm 4.58$ & $144 \pm 11.68^{*}$ & $143 \pm 10.96 *$ \\
\hline Systolic BP (mmHg) & $117 \pm 4.07$ & $125 \pm 2.68$ & $131 \pm 3.48^{*}$ \\
\hline Diastolic BP (mmHg) & $72 \pm 2.00$ & $78 \pm 1.16 *$ & $79 \pm 1.65^{*}$ \\
\hline HR (bpm) & $71 \pm 3.93$ & $68 \pm 1.82$ & $75 \pm 3.02$ \\
\hline
\end{tabular}

* $p<0.05$ vs. active group; BMI: Body Mass Index; HDL: High-density lipoprotein; LDL: Low-density lipoprotein; VLDL: Very Low Density Lipoprotein; BP: Blood Pressure; HR: Heart rate. Data are represented as mean $+/$ - SEM.

We observed a significant difference in energy expenditure between the active group (9.25 $\pm 0.18 \mathrm{MET})$ versus the moderate active group (7.84 $\pm 0.08 \mathrm{MET})$ and least active group $(6.33 \pm 0.34 \mathrm{MET})$ (Figure 1A).

There was no significant difference between the groups regarding the fasting blood level of fasting blood glucose, cholesterol, low density lipoprotein (LDL) and very low-density lipoprotein (VLDL) (Table 1). However, we found that the less active group had lower levels of high-density lipoproteins (HDL) (42 \pm $2.43 \mathrm{mg} / \mathrm{dL}$ ) compared to the active group ( $52 \pm 3.08 \mathrm{mg} / \mathrm{dL}$ ) (Figure 1-D). In addition, the moderate active and the less active groups had higher values of blood triglycerides $(144 \pm 11.68 \mathrm{mg} / \mathrm{dL}$ and $143 \pm$ $10.96 \mathrm{mg} / \mathrm{dL}$ respectively) when compared to the active group (105 $\pm 4.58 \mathrm{mg} / \mathrm{dL})$ (Table 1 . Figure $1-\mathrm{C})$.

The systolic blood pressure was higher in the less active group (131 $\pm 3.5 \mathrm{mmHg})$ compared to the active group $(117 \pm 4.1 \mathrm{mmHg})$. The same was observed for diastolic blood pressure (DBP). We noticed a reduction in DBP in the active group $(72 \pm 3.93 \mathrm{mmHg})$ in comparison to the moderate active $(78 \pm 1.16$ 
$\mathrm{mmHg})$ and the less active groups $(79 \pm 1.65 \mathrm{mmHg})$ (Figure 1-B). There was no significant difference between groups with respect to heart rate (Table 1$)$.

Regarding HRV, the active group showed an increase in the variance of RR interval (1849.6 $\left.\pm 387.7 \mathrm{~ms}^{2}\right)$ as compared to the moderate active ( $\left.892.1 \pm 141.9 \mathrm{~ms}^{2}\right)$ and to the less active groups $(972.3 \pm 285.2$ $\mathrm{ms}^{2}$ ) (Figure 2-A). Moreover, the active group showed higher absolute HF component $\left(\mathrm{ms}^{2}\right)$ as compared to the other groups (Table 2). The sympathetic-vagal balance was higher in the moderate active (2.6 \pm $0.3)$ and the less active groups $(2.5 \pm 0.2)$ as compared to the active group $(1.6 \pm 0.2)$ (Figure 2-B).

Table 2. The Heart Rate Variability in the frequency domain.

\begin{tabular}{lccc}
\hline & Active (n=13) & Moderate Active $(\mathrm{n}=19)$ & Less Active $(\mathrm{n}=17)$ \\
\hline $\mathrm{LF}\left(\mathrm{ms}^{2}\right)$ & $331.8 \pm 102.3$ & $182.5 \pm 40.3$ & $158.1 \pm 41.4$ \\
$\mathrm{HF}\left(\mathrm{ms}^{2}\right)$ & $298.9 \pm 80.3$ & $78.5 \pm 20.8^{*}$ & $63.2 \pm 16.2^{*}$ \\
\hline \% LF & $57.7 \pm 3.5$ & $68.6 \pm 2.4^{*}$ & $69.3 \pm 2.2^{*}$ \\
\hline \%HF & $42.3 \pm 3.5$ & $31.4 \pm 2.4^{*}$ & $30.7 \pm 2.2^{*}$ \\
\hline
\end{tabular}

* $p<0.05$ vs. active group; LF: Low Frequency band of RR; HF: High Frequency band of RR. Data are represented as mean +/-SEM.

\section{Discussion}

Considering the increase in the age of the population and consequent increase in cardiovascular risk, in addition to the increasingly sedentary changes in the lifestyle of the population, our findings showed that the less active group had higher SBP and DBP values compared to the active group. The most active group showed higher VAR RR values and the IP HF band in relation to the less active group, in addition to a lower sympathovagal balance, indicating lower cardiac sympathetic modulation.

The habitual physical activity questionnaire (PAQ), used in this study, allowed us to verify the energy expenditure dispensed in daily activities during the 12-month period. Through this questionnaire, we divided the participants of this study into three groups to analyze the influence of physical activity on quality of life and health of people over 60 years of age (9). The least active group presented the lowest value of energy expenditure, being considered as a sedentary group. It is worth noting that in the Western world, sedentary lifestyle, as a risk factor for health, is only surpassed by tobacco consumption and is highly representative $(14,15)$. The global challenge of physical inactivity is further amplified by the risk it carries. We have observed in some studies enough evidence that $6-10 \%$ of all deaths from noncommunicable diseases worldwide can be attributed to physical inactivity, and this percentage is even higher for specific diseases (eg. 30\% for the ischemic heart disease). In 2007, 5.3 to 5.7 million of 
deaths worldwide from noncommunicable diseases could have been avoided if, in theory, people who were inactive were sufficiently active (16).

In addition, some serious health problems are associated with obesity, including type II Diabetes and cardiovascular disease. White adipose tissue is not only a place for energy storage, but it is also an active endocrine organ that secretes more than 50 cytokines/chemokines and bioactive mediators called adipocytokines that are involved in lipid metabolism, insulin sensitivity, immunity, angiogenesis and inflammation (17).

According to Santanasto (2017) with aging there is a reduction in muscle mass and an increase in the accumulation of body fat, which may be related to food and cultural habits (18). The least active group presented higher values of SBP and DBP compared to the active group. In this sense, it is worth remembering that CVD mortality increases considerably with elevated blood pressure.

Regarding the results obtained from the lipid profile, the less active group presented a high level of triglycerides and a reduction in the level of HDL, if changes in LDL and VLDL in relation to the other groups. Vellosa et al. (2013) observed that the decrease in the plasma concentration of HDL is strongly related to the development of endothelial dysfunction and, consequently, to CAD (19).

Furthermore, some studies have shown that heart rate variability (HRV) is reduced in stress conditions and in many chronic diseases, and may even predict the development and prognosis of some diseases (6). In a recent study of our group, we showed that sedentary women presented higher heart rate, lower variance of RR interval and RMSSD and higher cardiac sympathovagal balance (LF/HF) both at rest and in response to the mental stress test in comparison to physically active women (20). In the HRV spectral analysis, the less active group showed lower IP VAR and IP HF band in relation to the active group, besides a higher sympathovagal balance, indicating a higher cardiac sympathetic modulation.

According to our findings, some authors mention that there are losses in HRV with aging and a less active life $(21,22)$. It is important to emphasize that the reduction in HRV is related to a decrease in vagal activity over the sinus node and may be associated with other risk factors and increased sympathetic activity related to high plasma noradrenaline concentration in individuals over 65 years (23).

Studies show that higher HRV values indicate better adaptation and control of the sympathetic and parasympathetic nervous system, and active individuals have a better index in the time and frequency domain due to the increase in vagal tone caused by the practice of physical activity (24). Recent study showed that sedentary offspring of hypertensives, in contrast with the strength-trained group, presented impairment of total variance of RR interval, as well as an increase in cardiac sympathovagal balance (25).

Our results corroborate these findings, since the active group showed higher VAR RR and AF component $\left(\mathrm{m}^{2}\right)$, as well as a better sympathovagal balance. In addition, studies have demonstrated that cardiovascular autonomic dysfunction, evidenced by a reduction in HRV, is associated with higher levels 
of inflammatory mediators such as TNF-a and IL-6 (26). In addition, a study of our group showed that cardiovascular autonomic dysfunction precedes metabolic dysfunction in male mice submitted to chronic consumption of fructose (27). Finally, studies show that the vagus nerve can modulate the inflammatory response and oxidative stress in some pathophysiological situations $(28,29)$.

In this sense, the results of the present study suggest that the best cardiac autonomic modulation observed in the active elderly group may be associated with the reduction of inflammatory mediators and oxidative stress, which together could be related to the reduction of cardiovascular and metabolic risk in this phase of life.

In fact, regardless of age, the practice of physical activity seems to be beneficial and helps increase the standard curve of physiological aging (18). In addition, changes in lifestyle are recommended in the primary prevention of hypertension, and in individuals with borderline BP. These changes may reduce BP as well as cardiovascular mortality. The main non-medicinal recommendations for the primary prevention of hypertension are: healthy eating, controlled consumption of sodium and alcohol, potassium intake, sedentary lifestyle and smoking (11).

\section{Conclusion}

Our findings highlight the importance of a physically active life to prevent cardiometabolic dysfunctions and for a healthier aging, enabling improvements in quality of life and fewer comorbidities associated with ageing. However, more studies are needed to consolidate our findings, which indicate a major influence of physical activity level on increased cardiovascular risk, assessed by classic markers such as BMI, lipid profile and BP, but also by heart rate variability.

\section{Abbreviations}

HRV-Heart Rate Variability

BP-Blood Pressure

CVD-Cardiovascular Disease

BMI- Body Mass Index

MET - Energy Expenditure

LDL-Low Density Lipoproteins

VLDL-Very Low Density Lipoproteins

HDL-High Density Lipoproteins

DBP- Diastolic Blood Pressure 
LF-Low Frequency band of RR

HF-High Frequency band of RR

SBP-Sistolic Blood Pressure

VAR RR-Variance of RR interval

IP HF- Pulse Interval of High Frequency

PAQ- Habitual Physical Activity Questionnaire

CAD-Coronary Artery Disease

RMSSD-Square Root Of The Mean Squared Differences Of Successive N-N Intervals

LF/HF-Sympathovagal Balance

TNF-a-Tumor Necrosis Factor

IL-6- Interleukin

HR-Heart Rate

FFT- Fast Fourier Transform

\section{Declarations}

Ethics approval and consent to participate: The study participants were informed about the procedures and signed a free and informed consent form. The Project was submitted to the Research Ethics Committee (COEP/USJT) under number 0067.0.219.000-09.

Consent for publication: "Not applicable"

Availability of data and materials: The datasets used and/or analysed during the current study are available from the corresponding author on reasonable request.

Conflict of Interest: The authors declare that the results of the study are presented clearly, honestly, and without fabrication, falsification, or inappropriate data manipulation. There is no conflict of interest between authors.

Acknowledgments and Funds: This work was supported by the CNPq 4673001/2014-3; CNPq: 476373/2012-3. CNPq HASCA: 467300/2014-3.

Author Contributions: AV, NB, MS, CMS, ICS, MV, MLJM and KA contributed conception and design of the study; AV, MS, NB and CMS organized the database; AV, MV, MLJM and KA performed the statistical 
analysis; AV wrote the first draft of the manuscript; MS, MV, MLJM and KA wrote sections of the manuscript. All authors contributed to manuscript revision, read and approved the submitted version.

\section{References}

1. Beard JR, Officer A, de Carvalho IA, Sadana R, Pot AM, Michel J-P, et al. The World report on ageing and health: a policy framework for healthy ageing. The Lancet. 2016;387(10033):2145-2154.

2. North BJ, Sinclair DA. The intersection between aging and cardiovascular disease. Circ Res. 13 de abril de 2012;110(8):1097-108.

3. Nichols M, Townsend N, Scarborough P, Rayner M. Cardiovascular disease in Europe 2014: epidemiological update. Eur Heart J [Internet]. 2014 [citado 17 de maio de 2015];2950-9. Disponível em: http://eurheartj.oxfordjournals.org/content/early/2014/08/12/eurheartj.ehu299?rss\%253D1=

4. Simão AF, Précoma DB, Andrade JP de, Correa Filho H, Saraiva JFK, Oliveira GMM de. I cardiovascular prevention guideline of the Brazilian Society of Cardiology-executive summary. Arq Bras Cardiol. 2014;102(5):420-431.

5. Go AS, Mozaffarian D, Roger VL, Benjamin EJ, Berry JD, Blaha MJ, et al. Heart disease and stroke statistics-2014 update: a report from the American Heart Association. Circulation [Internet]. 2014 [citado 17 de maio de 2015];129(3):28-292. Disponível em:

http://www.ncbi.nlm.nih.gov/pubmed/24352519

6. Prinsloo GE, Rauch HG, Derman WE. A brief review and clinical application of heart rate variability biofeedback in sports, exercise, and rehabilitation medicine. Physician Sports Med [Internet]. 2014 [citado 19 de maio de 2015];42(2):88-99. Disponível em:

https://physsportsmed.org/doi/10.3810/psm.2014.05.2061

7. Soares-Miranda L, Sattelmair J, Chaves P, Duncan GE, Siscovick DS, Stein PK, et al. Physical activity and heart rate variability in older adults: the Cardiovascular Health Study. Circulation. 2014;129(21):2100-2110.

8. Bueno HM, Sartori M, Macedo HR, Moraes-Silva IC, Aletti F, Irigoyen MC, et al. Bicycling for transportation improves heart rate variability in young adults. J Sports Med Phys Fitness [Internet]. 2015 [citado 11 de fevereiro de 2016]; Disponível em: http://europepmc.org/abstract/med/26684436

9. Florindo AA, Latorre M do RD de. Validation and reliability of the Baecke questionnaire for the evaluation of habitual physical activity in adult men. Rev Bras Med Esporte. 2003;9(3):129-135.

10. Baecke JA, Burema J, Frijters JE. A short questionnaire for the measurement of habitual physical activity in epidemiological studies. Am J Clin Nutr [Internet]. 1982 [citado 27 de outubro de 2015];36(5):936-942. Disponível em: http://ajcn.nutrition.org/content/36/5/936.short

11. Whelton PK, Carey RM, Aronow WS, Casey DE, Collins KJ, Himmelfarb CD, et al. 2017 ACC/AHA/AAPA/ABC/ACPM/AGS/APhA/ASH/ASPC/NMA/PCNA guideline for the prevention, detection, evaluation, and management of high blood pressure in adults: a report of the American 
College of Cardiology/American Heart Association Task Force on Clinical Practice Guidelines. J Am Coll Cardiol. 2017;24430.

12. Loimaala A, Sievanen H, Laukkanen R, Parkka J, Vuori I, Huikuri H. Accuracy of a novel real-time microprocessor QRS detector for heart rate variability assessment. Clin Physiol [Internet]. 1999 [citado 30 de outubro de 2015];19(1):84-88. Disponível em: http://onlinelibrary.wiley.com/doi/10.1046/j.1365-2281.1999.00152.x/full

13. Rocha AC, Sartori M, Rodrigues B, De Angelis K. Influence of the number of sets in cardiovascular and autonomic adjustments to resistance exercise in physically active men. Rev Bras Med Esporte [Internet]. 2013 [citado 30 de outubro de 2015];19(5):332-335. Disponível em: http://www.scielo.br/scielo.php?pid=S1517-86922013000500006\&script=sci_arttext

14. Ford ES, Caspersen CJ. Sedentary behaviour and cardiovascular disease: a review of prospective studies. Int J Epidemiol. 2012;41(5):1338-1353.

15. Henson J, Yates T, Biddle SJ, Edwardson CL, Khunti K, Wilmot EG, et al. Associations of objectively measured sedentary behaviour and physical activity with markers of cardiometabolic health. Diabetologia. 2013;56(5):1012-1020.

16. Kohl HW, Craig CL, Lambert EV, Inoue S, Alkandari JR, Leetongin G, et al. The pandemic of physical inactivity: global action for public health. The Lancet [Internet]. 2012 [citado 22 de maio de 2015];380(9838):294-305. Disponível em:

http://www.sciencedirect.com/science/article/pii/S0140673612608988

17. Sindhu S, Thomas R, Shihab P, Sriraman D, Behbehani K, Ahmad R. Obesity is a positive modulator of IL-6R and IL-6 expression in the subcutaneous adipose tissue: significance for metabolic inflammation. PloS One [Internet]. 2015 [citado 16 de novembro de 2015];10(7):e0133494. Disponível em: http://dx.plos.org/10.1371/journal.pone.0133494

18. Santanasto AJ, Goodpaster BH, Kritchevsky SB, Miljkovic I, Satterfield S, Schwartz AV, et al. Body composition remodeling and mortality: the health aging and body composition study. J Gerontol Ser A. 2017;72(4):513-519.

19. Vellosa JCR, Parabocz GC, Manente FA, Ribas JT, Lima LW. Metabolic and inflammatory changes in oxidative stress situations. Rev Cienc Basic Farm Apl. 2013;34(3):305-312.

20. Zaffalon Júnior JR, Viana AO, de Melo GEL, De Angelis K. The impact of sedentarism on heart rate variability (HRV) at rest and in response to mental stress in young women. Physiol Rep. 2018;6(18):e13873.

21. Voss A, Schroeder R, Heitmann A, Peters A, Perz S. Short-term heart rate variability-influence of gender and age in healthy subjects. PloS One. 2015;10(3):e0118308.

22. Almeida-Santos MA, Barreto-Filho JA, Oliveira JLM, Reis FP, da Cunha Oliveira CC, Sousa ACS. Aging, heart rate variability and patterns of autonomic regulation of the heart. Arch Gerontol Geriatr. 2016;63:1-8.

23. Wichi RB, De Angelis K, Jones L, Irigoyen MC. A brief review of chronic exercise intervention to prevent autonomic nervous system changes during the aging process. Clinics [Internet]. 2009 [citado 
16 de novembro de 2015];64(3):253-258. Disponível em: http://www.scielo.br/scielo.php? pid=S1807-59322009000300017\&script=sci_arttext

24. Vanderlei LCM, Pastre CM, Hoshi RA, Carvalho TD de, Godoy MF de. Basic notions of heart rate variability and its clinical applicability. Braz J Cardiovasc Surg. 2009;24(2):205-217.

25. Santa-Rosa FA, Shimojo GL, Sartori M, Rocha AC, Francica JV, Paiva J, et al. Familial history of hypertension-induced impairment on heart rate variability was not observed in strength-trained subjects. Braz J Med Biol Res. 2018;51(12).

26. Bossenmaier B, Strack V, Stoyanov B, Krützfeldt J, Beck A, Lehmann R, et al. Serine residues $1177 / 78 / 82$ of the insulin receptor are required for substrate phosphorylation but not autophosphorylation. Diabetes [Internet]. 2000 [citado 22 de junho de 2015];49(6):889-95. Disponível em: http://diabetes.diabetesjournals.org/content/49/6/889.short

27. De Angelis K, Senador DD, Mostarda C, Irigoyen MC, Morris M. Sympathetic overactivity precedes metabolic dysfunction in a fructose model of glucose intolerance in mice. Am J Physiol-Regul Integr Comp Physiol [Internet]. 2012 [citado 19 de maio de 2015];302(8):950-7. Disponível em: http://ajpregu.physiology.org/content/302/8/R950.short

28. Borovikova LV, Ivanova S, Zhang M, Yang H, Botchkina Gl, Watkins LR, et al. Vagus nerve stimulation attenuates the systemic inflammatory response to endotoxin. Nature [Internet]. 2000 [citado 16 de maio de 2015];405:458-62. Disponível em:

http://www.nature.com/articles/doi:10.1038\%2F35013070

29. Van Gaal LF, Mertens IL, Christophe E. Mechanisms linking obesity with cardiovascular disease. Nature [Internet]. 2006 [citado 22 de junho de 2015];444(7121):875-80. Disponível em: http://www.nature.com/nature/journal/v444/n7121/abs/nature05487.html

\section{Figures}


A

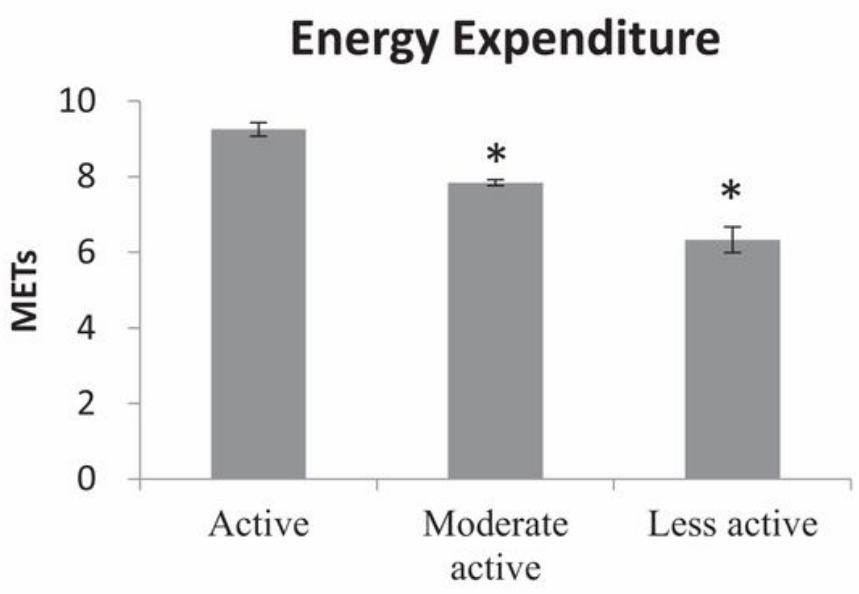

\section{C}

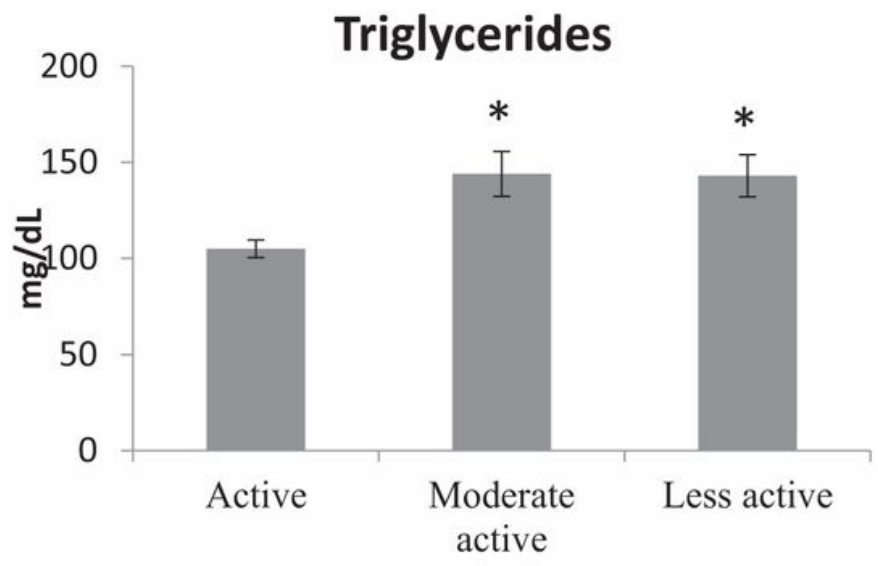

B

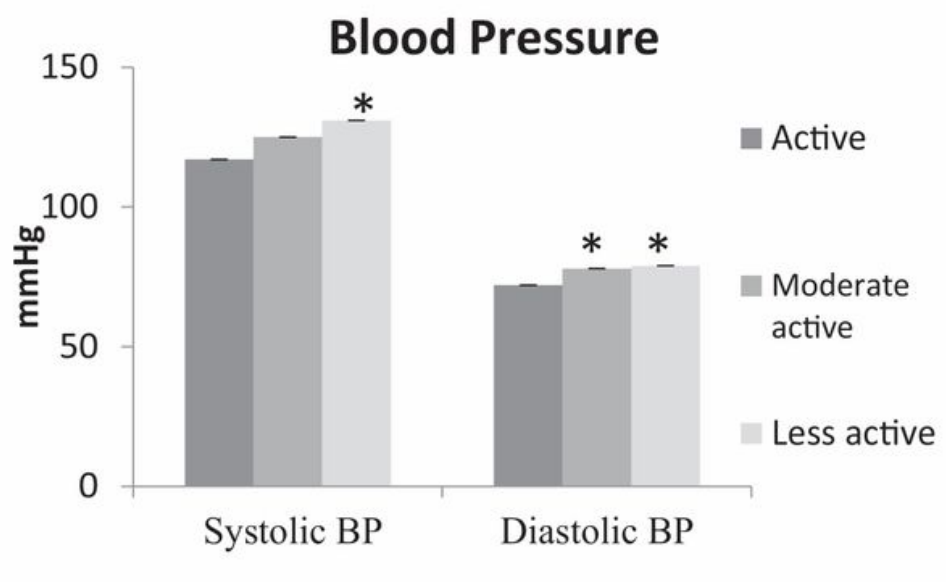

D

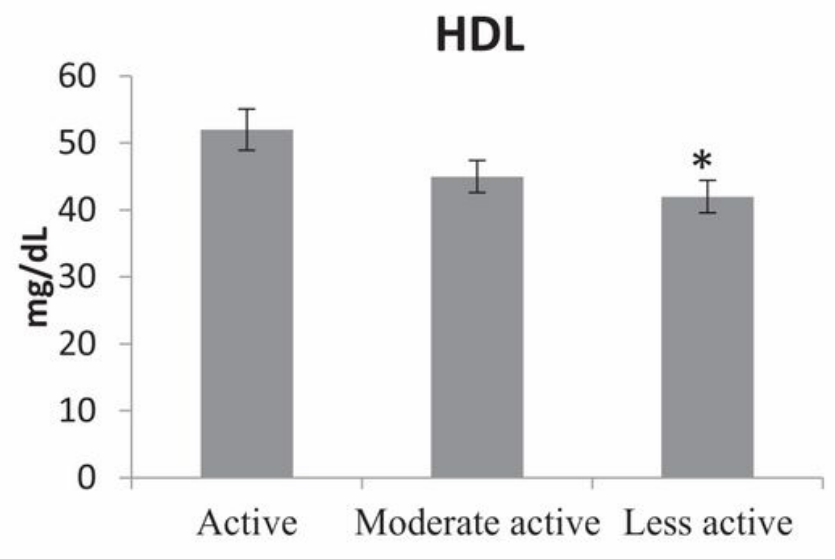

Figure 1

Energy Expenditure (A), Blood Pressure (B), Triglycerides (C) and High-density Lipoprotein (D) in the groups studied. * $\mathrm{p}<0.05$ vs. active group. Data are represented as mean +/- SEM.

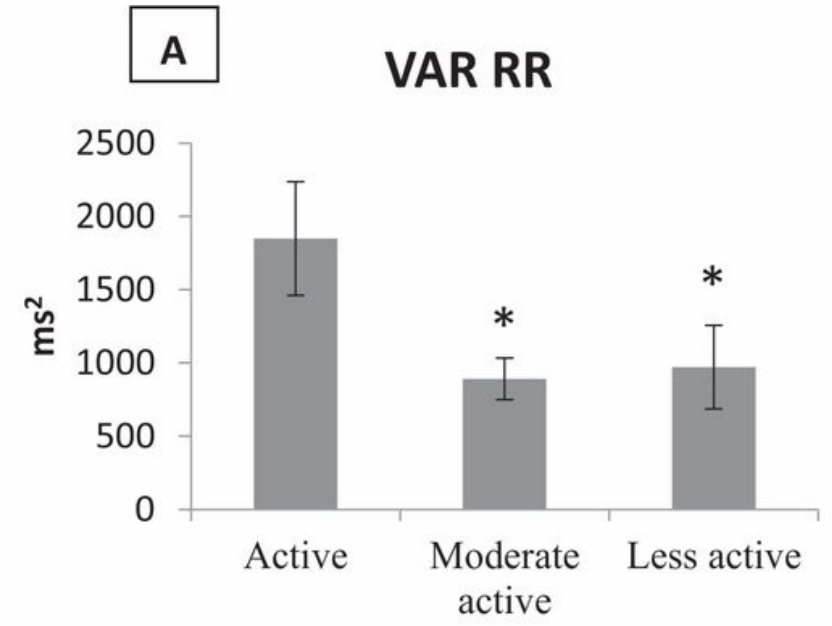

\section{B}

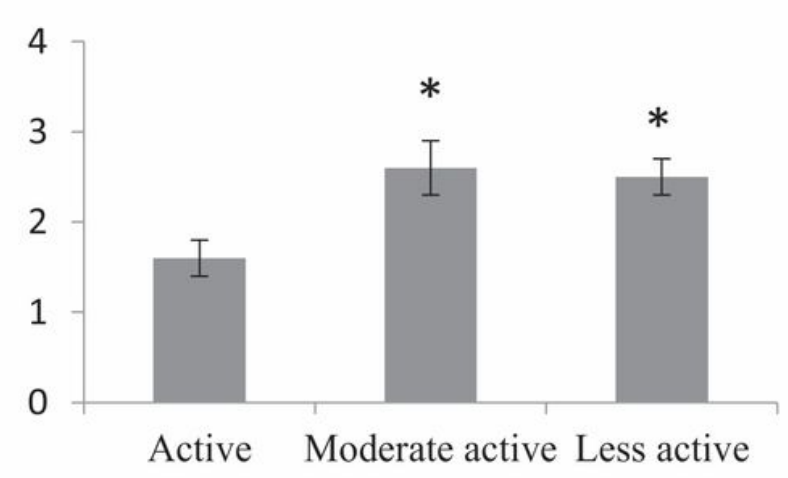


Figure 2

Variance of RR (VAR RR) (A) and sympathetic-vagal balance (LF/HF) (B) in the groups studied. * $p<0.05$ vs. active group. Data are represented as mean +/- SEM. 